American Journal of Agricultural and Biological Sciences 6 (2): 267-272, 2011

ISSN 1557-4989

(C) 2011 Science Publications

\title{
Antagonist capacity of Newly Isolated Strains of Pseudomonas Fluorescens against Three Important Phytopathogenic Bacteria
}

\author{
${ }^{1}$ Reynaldo De La Cruz-Quiroz, ${ }^{2}$ Catalina Chavez, ${ }^{2}$ Marcela Hernandez, \\ ${ }^{1}$ Raul Rodriguez, ${ }^{3}$ Daniel Hernandez and ${ }^{1}$ Cristobal Noe Aguilar \\ ${ }^{1}$ Department of Food Research, School of Chemistry, Universidad Autonoma de Coahuila, \\ ${ }^{2}$ Center of Applied Microbiology, GreenCorp Biorganiks de Mexico SA de CV, \\ ${ }^{3}$ Department of Agricultural Parasitology, Universidad Autonoma Agraria, \\ "Antonio Narro", Buenavista, Saltillo, Coahuila, Mexico
}

\begin{abstract}
Problem statement: Phytopatogenic bacteria cause several damages to plants with important economical consequences. They provoke losses of product quality affecting all commercial chain of crops, for this reason, their control is a priority. Approach: We evaluated antagonist capacity of newly isolated Pseudonomas fluorescens strains against three important phytopatogenic bacteria (Clavibacter michiganensis, Xanthomonas axonopodis and Erwinia carotovora). Soils from commercial cropping of Capsicum annum $L$ of several Mexican regions were used to isolate $P$. fluorescens strains. Results: Isolates producing flourescein were purified on King B agar and biochemically identified. Crude extracts with and without cells were produced in King B broths and their antagonist capacities were evaluated by the plate diffusion procedure on nutritive agar. Conclusion: Obtained results demonstrated that cell free extracts exhibited a limited antagonist capacity in comparison of those extracts with cells, which showed an excellent capacity to inhibit the growth of $C$. michiganensis, $X$. axonopodis and $E$. carotovora, demonstrating the intracellular nature of the bioactive metabolites associated to bacterial growth inhibition.
\end{abstract}

Key words: Pseudonomas fluorescens, ellular nature, Mexican agriculture, Phytopatogen bacteria, foliar spots, Free Cell crude extracts (FC), fluorescens strains, polypeptone, microorganisms, economical losses

\section{INTRODUCTION}

Mexican agriculture present different troubles among which are included: severe changes in temperatures during the growing season, a growing desertification process and dissemination of several plant diseases characterized for a persistent resistance to chemical products. Plant diseases are caused by microorganisms provoking several symptoms like foliar spots, cell wall degradation, deformations, necrosis, rottenness of products. In Mexico, agricultural losses caused by microorganisms vary from 20-100 percent for some crops, these damages are in some cases higher than that calculated for around the world, however, in recent years there is a renewed interest to reduce the economical losses and to improve the quality and yield of crops using more friendly environment technologies under a organic agriculture philosophy.
C. michiganensis, $X$. axonopodis and E. carotovora are three phytopatogenic bacteria which cause important negative effects to agricultural commodities. C. michiganensis is an aerobic non-sporulating Grampositive plant pathogenic organism and depending of the subspecie it is the causal agent of bacterial canker of tomato (Lycopersicon esculentum Mill.), a disease in potatoes known as 'ring rot', infects maize (Zea mays), wheat and alfalfa (Eichenlaub et al., 2006; Kleitman et al., 2008). X. axonopodis is a gram negative and aerobic microorganism with rod shape and polar flagella. It can be found on the leaves, stems and fruit of citrus trees all around the world. This bacterium causes citrus cankers. The leaves, stems and fruits that are infected with $X$. axonopodis display lesions which take on yellow halo or ring shaped appearances (Vidhyasekaran et al., 2001; Khodakaramian and Swings, 2011). E. carotovora is a rod shaped bacterium

Corresponding Author: C.N. Aguilar, Department of Food Research, School of Chemistry, Universidad Autonoma de Coahuila, “Antonio Narro", Buenavista, Saltillo, Coahuila, Mexico Tel: +52 844 4161238, Fax: 528444159534 
which infects a variety of vegetables and plants including carrots, potatoes, cucumbers, onions, tomatoes, lettuce and ornamental plants like iris (Laurent et al., 2001; Chernyshov et al., 2007). These widespread microbes can be found in soil, guts of insects, water and suspended aerosols in air.

Biocontrol of this kind of phytopatogens requires of effective and potent microorganisms in order to reduce damages and economical losses. Pseudomonas fluorescens is a bacterium with antagonist properties which has not been used as others due that its mechanisms of action are diverse and still remain confuse. $P$. flourescens is a gram negative rod organism which promotes growth of some plants due its capactity to produce growth-stimulating substances like auxins, giberelins and cytokinins. Physiologically, this microorganism promotes seed germination, increases root formation and accelerate plant growth (Moore et al., 2006; Babalola, 2010).

In the present study, the antagonist capacity of newly isolated Pseudonomas fluorescens strains against three important phytopatogenic bacteria (Clavibacter michiganensis, Xanthomonas axonopodis and Erwinia carotovora) was evaluated.

\section{MATERIALS AND METHODS}

Isolation of $\mathbf{P}$. fluorescens strains: Nine soil samples from commercial production lots of pepper (Capsicum annum $L$ ) were used in this study. Soil samples were collected from the Mexican states of Chihuahua, Sinaloa, Veracruz, Nayarit and Guerrero by workers of GreenCorp Bioorganiks de Mexico SA de CV.

Soil samples were immediately processed to Pseudomonas fluorescens strains isolation. Series of 7 decimal dilutions with distilled water at room temperature were used. Aliquots of $100 \mu \mathrm{L}$ from the last three dilutions were inoculated on King B agar plates, which were incubated at $27 \pm 2^{\circ} \mathrm{C}$ for $24 \mathrm{~h}$. Presence of fluorescence on UV light was used to select those putative $P$. fluorescens colonies. Each colony was re-inoculated in the same culture medium for its purification. After incubation, each colony was morphologically analyzed using microscopy and the Gram technique. Those Gram negative rods producing fluorescence were selected for this study.

Identification and conservation of $P$. fluorescens strains: After selection of pure strains, these were grown in several culture media for a biochemical characterization and avoid the presence of $P$, putida and $P$ aureginosa, which also produce similar pigments.
Those colonies indentified as $P$ fluorescens were conserved in slants at refrigeration and under cryoconserved at $-20^{\circ} \mathrm{C}$.

Phytopatogen bacteria: The phytopatogens used in this study were Clavibacter michiganensis, Xanthomonas axonopodis and Erwinia carotovora and they belong to The Center of Applied Microbiology (CEMAP) collection, GreenCorp Biorganiks de Mexico SA de CV. Saltillo, Coahuila, Mexico. All three bacteria were grown in $250 \mathrm{ml}$ Erlenmeter flasks with $100 \mathrm{ml}$ of nutritive broth enriched with potato infusion at $30^{\circ} \mathrm{C}$ by $24 \mathrm{~h}$.

Culture conditions of $\boldsymbol{P}$. fluorescens: For production of crude extracts with and without cells, two culture media were compared. Both media contained a base formulated (per liter) with glycerol $(10 \mathrm{~g})$, dibasic potassium phosphate $(1.5 \mathrm{~g})$, magnesium sulfate $(1.5 \mathrm{~g})$, but one of them enriched with $20 \mathrm{~g}$ of potato starch and the other with $20 \mathrm{~g}$ of polypeptone. Cell concentration was evaluated by counting in a Neubauer chamber after $24 \mathrm{~h}$ of culture time at $28^{\circ} \mathrm{C}$. After culture medium was selected, influence of $\mathrm{pH}(6.5,7.0$ and 7.5) and temperature $\left(25,30\right.$ and $\left.35^{\circ} \mathrm{C}\right)$ were evaluated;

Non Free Cell crude extracts (NFC): Selected $P$. fluorescens strains were grown on $500 \mathrm{ml}$ culture bottles containing $100 \mathrm{~mL}$ of King B Broth at $28^{\circ} \mathrm{C}$ during $24 \mathrm{~h}$ in a innova $44^{\circledR}$ shaker at $200 \mathrm{rpm}$. An inoculation level of $1 \times 10^{6}$ cells per culture bottle was used. After culture time, all culture bottle content was used to evaluated the antagonist capacity.

Free Cell crude extracts (FC): Selected $P$. fluorescens strains were grown under the same culture conditions described above. After culture time, the content was put into conic tubes and centrifuged at $6000 \mathrm{rpm}$ during 15 $\min$ at $4^{\circ} \mathrm{C}$. Supernatant was carefully removed and considered as free cell crude extracts. To remove cells and works with a real free cell crude extract, each sample was filtered through $0.45 \mu \mathrm{m}$ sterile Nylon membrane (Millipore ${ }^{\circledR}$ ). Obtained filtrates were used to evaluate their antagonist capacity.

Antagonist capacity of crude extracts: Plates of nutritive agar were completely inoculated with each phytopatogenic bacteria. Four little cavities $(5 \mathrm{~mm}$ diameter) were made on the agar surface and then were filled with an aliquot of $100 \mathrm{~mL}$ of crude extracts. Plates were incubated at $30^{\circ} \mathrm{C}$ for $24 \mathrm{~h}$. After that, inhibition halos were measured. 
Experimental design and data analysis: Tests for determination of culture conditions and antagonist capacity were established under a completely randomized block design with a factorial fix. ANOVA procedure was used to evaluate each effect and when it was needed a comparison test of mean values (Tukey Test) was used. SAS software was used for data analysis.

\section{RESULTS}

In this study, several experimental steps were conducted to evaluate the biological potential of newly isolated strains of $P$. fluorescens.

Isolation of $\boldsymbol{P}$. fluorescens strains: The protocol used for isolation permitted to obtain suspected colonies of $P$. fluorescens from the soil samples. Simple microscopy revealed Gram-negative and short rods. Pigment production was easily revealed when plates were put under UV light. It is important to note that $P$. fluorescens produces pyoverdins (Fig. 1), bioactive molecules of high affinity called siderophores, associated to colonization of rhizosphere and very well studied in the models $P$. aeruginosa and $P$. putida (Redly and Poole, 2003; Molina et al., 2005). All morphological characteristics of isolated strains were compared with a control strain ( $P$. fluorecsens $\mathrm{M}$ f1).

Identification and conservation of $\boldsymbol{P}$. fluorescens strains: Selected strains were identified by biochemical differentiation. Table 1 shows the biochemical behavior of selected strains. All strains had similar biochemical behaivor to control, except sample M 6a, which was immobile. P. fluorescens does not ferment glucose, lactose and sucrose, neither produces gas from fermentation. In contrast, it grows descarboxylating ornitine and lysine, with motility and producing oxidase activity.

Culture conditions of $\boldsymbol{P}$. fluorescens: Culture conditions were established using the growth of M If strain (control) as criterion of selection. Figure 2 shows the effect of culture media, $\mathrm{pH}$ and temperature on bacterial growth. It is important to note that the experimental design used (sequenced mono-factorial fix) permitted a significant increase of number of Colony-Forming Units (CFU). The maximun $P$. fluorescens growth was achieved on a culture medium based on polypeptone, with an initial $\mathrm{pH}$ of 7.5 and a temperature of $35^{\circ} \mathrm{C}$.
Table 1: Biochemical differentiation of P. fluorescens strains

\begin{tabular}{lllllll}
\hline & Glu-Suc & \multicolumn{5}{c}{ Ornitine } \\
& -Lac & Gas & Motility & \multicolumn{2}{l}{ Descarb } & \multicolumn{2}{l}{ Descarb. oxidase } \\
\hline M 6a & $(-)$ & $(-)$ & $(-)$ & $(+)$ & $(+)$ & $(+)$ \\
M 6b & $(-)$ & $(-)$ & $(+)$ & $(+)$ & $(+)$ & $(+)$ \\
M6c & $(-)$ & $(-)$ & $(+)$ & $(+)$ & $(+)$ & $(+)$ \\
M 4a & $(-)$ & $(-)$ & $(+)$ & $(+)$ & $(+)$ & $(+)$ \\
M 4b & $(-)$ & $(-)$ & $(+)$ & $(+)$ & $(+)$ & $(+)$ \\
M 4c & $(-)$ & $(-)$ & $(+)$ & $(+)$ & $(+)$ & $(+)$ \\
M 4d & $(-)$ & $(-)$ & $(+)$ & $(+)$ & $(+)$ & $(+)$ \\
M 1f & $(-)$ & $(-)$ & $(+)$ & $(+)$ & $(+)$ & $(+)$ \\
\hline
\end{tabular}

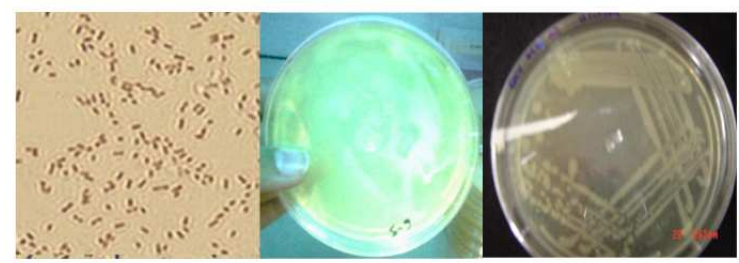

Fig. 1: Pyoverdine production (revealed under UV light) and morphology of $P$. fluorescens

Antagonist capacity of FC extracts. Plates of nutritive agar were completely inoculated with each FC extracts and the antagonist capacity was tested against the three phytopathogenic bacteria. Under culture conditions of $P$. fluorescens strains, none of FC extracts inhibited the growth of the phytopathogen bacteria.

Antagonist capacity of NFC extracts: Same assays conditions were used to evaluate the antagonist capacities of NFC extracts to inhibit the growth of phytopathogen bacteria. Figure 3 shows the inhibition of C. michiganensis growth. M6a and M1f strains showed the highest antagonist capacity against $C$. michiganensis. M6c strain also inhibited $C$. michiganensis growth while the remaining $P$. fluorescens strains did not show any antagonist capacity. Four $P$. fluorescens strains showed a strong antagonist capacity against $E$. carotovora (Fig. 4). M6b, M6c and M1f strains showed the highest antagonist capacity against this phytopathogenic bacteria. M6a strain also inhibited E. carotovora growth while the remaining $P$. fluorescens strains did not show any antagonist capacity. $X$. axonopodis growth was inhibited by the $P$. fluorescens strains M6c, M1f and M6a (Fig. 5).

The antagonist capacity of the new isolated $P$. fluorescens strains was evaluated under a completely randomized block design with 4 replicates. Analysis of variance is shown in Table 2, while the Tukey's range tests are presented in Table 3-4. 

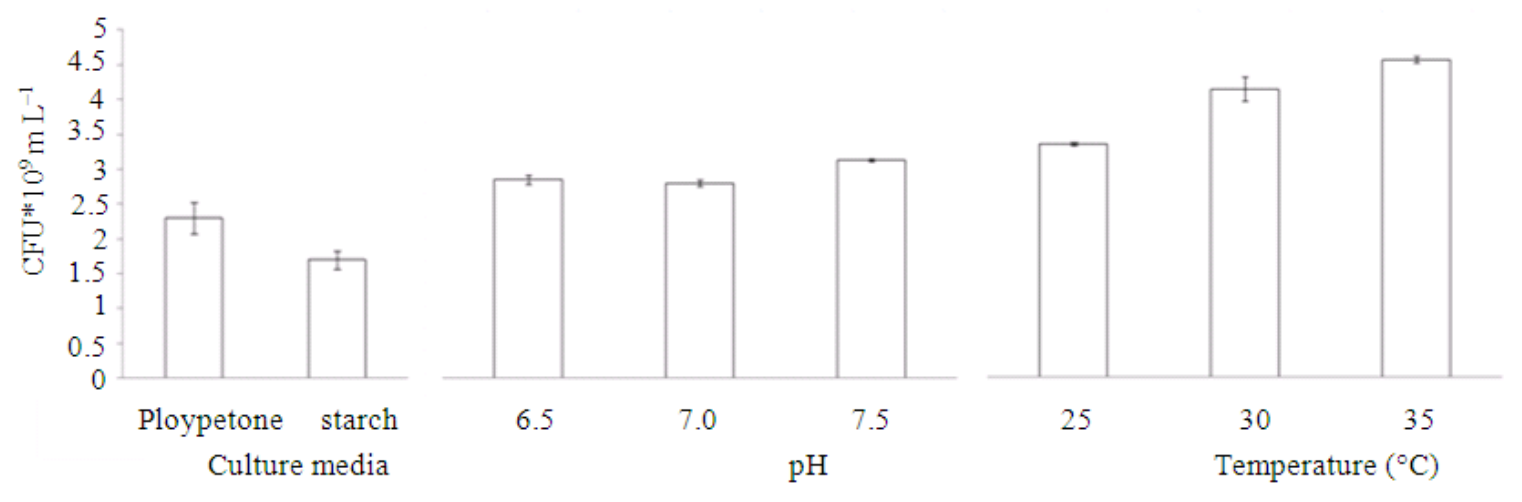

Fig. 2: Bacterial growth of $P$. fluorescens as affected by the culture media, $\mathrm{pH}$ and temperature level

Table 2: Analysis of variance for phytopathogenic bacteria growth inhibition by different $P$. fluorescens strains

\begin{tabular}{lllll}
\hline Source & df & Sum of squares & Mean square & F value \\
\hline Replicate & 3 & 0.018 & 0.006 & 0.38 \\
Antagonist strain (CA) & 3 & 15.409 & 5.136 & 311.18 \\
Pathogenic strain (CP) & 2 & 5.887 & 2.943 & 178.34 \\
Interaction CA-CP & 6 & 10.761 & 1.793 & $<0.001$ \\
Error & 33 & 0.544 & 0.016 & $<0.001$ \\
Total & 47 & 32.602 & & $<0.001$ \\
\hline
\end{tabular}

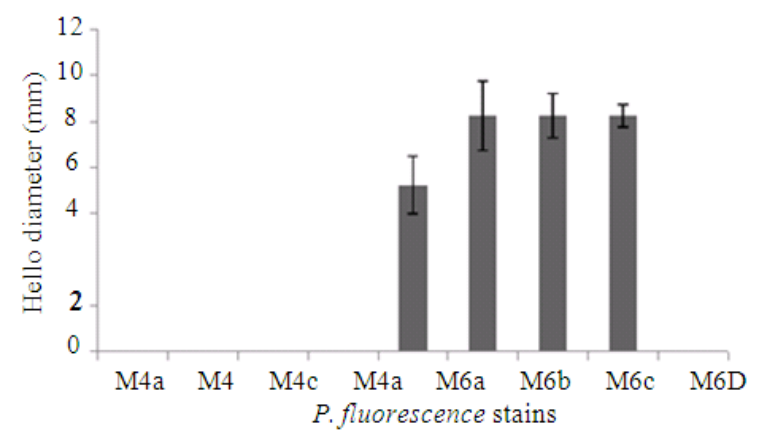

Fig. 3: Inhibition of $C$. michiganensis growth by $P$. fluorescens strains

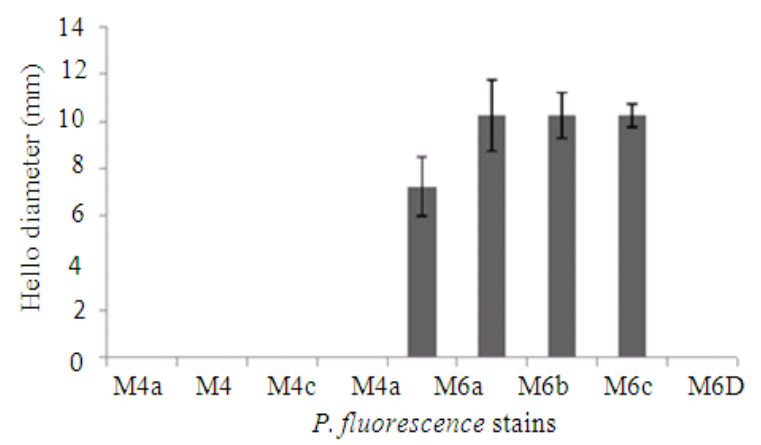

Fig. 4: Inhibition of E. carotovora growth by $P$. fluorescens strains

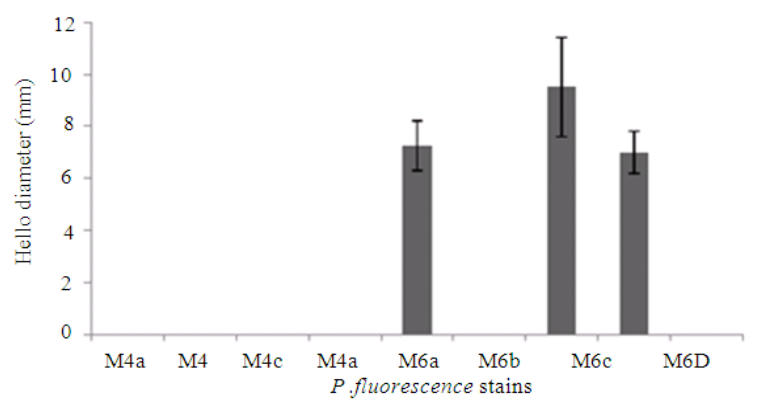

Fig. 5: Inhibition of $X$. axonopodis growth by $P$. fluorescens strains

\section{DISCUSSION}

Independent variables (CA and $\mathrm{CP}$ ) as their interaction (CA-CP) shown a significant effect on the inhibition of phytopathogenic bacteria growth, for this reason a comparative analysis of mean values was made between antagonist strains, demonstrating that M6b strain showed the lowest capacity of inhibition against the phytopathogen bacteria. The rest of antagonist strains were not significantly different (Table 3 ). While the results presented in Table 4 demonstrated that $E$. carotovora was the phytopathogen more inhibited by the $P$. fluorescens strains.

The significant difference found among the interaction antagonist-phytophatogen suggests a specific combination of $P$. fluorescens strains for the pathogenic bacteria inhibition, probably due to the pool of metabolites related to antagonist capacity. 
Table 3: P. fluorescens strains effect on Phytopathogenic bacteria growth inhibition

\begin{tabular}{ll}
\hline$P$. fluorescens strains & Halo diameter $(\mathrm{cm})$ \\
\hline $1 \mathrm{f}$ & $2.21 \mathrm{a}$ \\
$6 \mathrm{a}$ & $2.20 \mathrm{a}$ \\
6c & $2.10 \mathrm{a}$ \\
$6 \mathrm{~b}$ & $0.86 \mathrm{~b}$ \\
\hline
\end{tabular}

Treatment means followed by the same letter are not significant different according to the Tukey's range test $(\mathrm{p} \leq 0.05)$. Analysis was done using values were transformed to $\log (\mathrm{x}+1)$

Table 4: Phytopathogenic bacteria growth inhibition by different $P$. fluorescens strains

\begin{tabular}{ll}
\hline Phytopathogen & Mean value \\
\hline E. carotovora & $2.33 \mathrm{a}$ \\
X. axonopodis & $1.65 \mathrm{~b}$ \\
C. michiganensis & $1.54 \mathrm{~b}$ \\
\hline
\end{tabular}

Treatment means followed by the same letter are not significant different according to the Tukey's range test ( $\mathrm{p} \leq 0.05)$. Analysis was done using values were transformed to $\log (\mathrm{x}+1)$

M6a, M6c and M1f were the best antagonist bacteria, while $E$. carotovora was the phytopathogens more sensible to these new isolates of $P$. fluorescens.

Null formation of inhibition halos with FC extracts demonstrated the poor role of secreted metabolites to the culture broth to inhibite these pathogenic bacteria. In contrast, a wide range of possibilities can be considered to explain the antagonist capacity of isolates, including direct and indirect effects. Among the first, the diffusion phenomenon of soluble nutrients followed of an improved absorption of them by the plants was reported by Lifshitz et al. (1987) and Zhang et al. (2010). Antibiotic production by fungi and bacteria was mentioned by Dianez et al. (2007) and the release of phytohormones (auxines, gibberellins, cytocinnins and ethylene) was reported by Kulaeva and Prokoptseva (2004). Indirect effects include the increment in nitrogen fixation, which improve the number of root nodules and the increase of nitrogenase which also induce systemic resistance to the plant against the phytopathogens activity (Zhang et al., 1996; Intra et al., 2011).

\section{CONCLUSION}

In this study, the antagonist capacity of Newly Isolated Strains of Pseudomonas Fluorescens against Three Important Phytopathogenic Bacteria was clearly demonstrated, Cell free extracts exhibited a limited antagonist capacity in comparison of those extracts with cells, which showed an excellent capacity to inhibit the growth of $C$. michiganensis, $X$. axonopodis and $E$. carotovora, demonstrating the intracellular nature of the bioactive metabolites associated to bacterial growth inhibition.

\section{ACKNOWLEDGEMENT}

Researchers want to thank the financial support of National Council of Science and Technology of Mexico (project: 2009-INNOVAPYME-109692) and the technical support of GreenCorp Biorganils of Mexico, SA de CV.

\section{REFERENCES}

Chernyshov, S.V., Y.P. Ermakova, N.S. Zakharchenko, E.B. Georgievskaya and Y.I. Buryanov, 2007. Resistance to Erwinia carotovora of plants associated with modified bacteria, which have lost their pathogenicity. Doklady Biol. Sci., 1: 412-414. DOI: $10.1134 /$ S0012496607050274

Babalola, O.O., 2010. Beneficial bacteria of agricultural importance. Biotechnol. Lett., 11: 1559-1570. DOI: 10.1007/s10529-010-0347-0

Eichenlaub, R., K.H. Gartemann and A. Burguer, 2006. Clavibacter michiganensis a group of grampositive phytopathogenic bacteria. Plant Associated Bacteria, 3: 285-421. DOI: 10.1007/978-1-40204538-7_12

Dianez, F., M. Santos and J.C. Tello, 2007. Suppressive effects of grape marc compost on phytopathogenic oomycetes. Arch. Phytopathol. Plant Protect., 40: 1-18. DOI: $10.1080 / 03235400500222339$

Intra, B., I. Mungsuntisuk, T. Nihira, Y. Igarashi and W. Panbangred, 2011. Identification of actinomycetes from plant rhizospheric soils with inhibitory activity against Colletotrichum spp., the causative agent of anthracnose disease. BMC Res. Notes, 4: 98. DOI: 10.1186/1756-0500-4-98

Khodakaramian, G. and J. Swings, 2011. Genetic Diversity and Pathogenicity of Xanthomonas axonopodis Strains Inducing Citrus Canker Disease in Iran and South Korea. Ind. J. Microbiol., 2: 194199. DOI: $10.1007 / \mathrm{s} 12088-011-0103-8$

Kleitman, F., I. Barash, A. Burger, N. Iraki and Y.Falah, 2008. Characterization of a Clavibacter michiganensis subsp. michiganensis population in Israel. Eur. J. Plant Pathol., 4: 463-475. DOI: 10.1007/s10658-007-9264-Z

Kulaeva, O.N. and O.S. Prokoptseva 2004. Recent advances in the study of mechanisms of action of phytohormones. Biochemistry, 3: 233-247. DOI: 10.1023/B:BIRY.0000022053.73461.cd

Laurent, P., L. Buchon, J.F. Burini and N. Orange, 2001. Low $\mathrm{pH}$ and cold temperature combine to limit growth and pectate lyase production by psychortophic bacterium Erwinia carotovora spp. Carotovora MFCL0. Biotechnol. Lett., 23: 753756. DOI: 10.1023/A:1010392624650 
Lifshitz, R., J.W. Kloepper and M. Kozlowski, 1987. Growth promotion of canola (repeseed) seedlings by a strain of Pseudomonas putida under gnotobiotics conditions. Can. J. Microbiol., 3: 390395. DOI: $10.1139 / \mathrm{m} 87-068$

Molina, M.A., P. Godoy, M.I. Ramos-Gonzalez, N. Munoz and J.L. Ramos et al., 2005. Role of iron and the TonB system in colonization of corn seeds and roots by Pseudomonas putida KT2440. Environ. Microbiol., 7: 443-449. DOI: 10.1111/j.1462-2920.2005.00720.x

Moore, E., B. Tindall, V.M. Dos Santos, D. Pieper and J.L. Ramos, 2006. Nonmedical: pseudomonas. Prokariotes, 3: 643-703. DOI: 10.1007/0-38730746-X_21

Redly, G.A. and K. Poole, 2003. Pyoverdine-mediated regulation of FpvA synthesis in Pseudomonas aeruginosa: involvement of a probable extracytoplasmic-function sigma factor. J. Bacteriol., 185: 1261-1265. DOI: 10.1128/JB.185.4.1261-1265.2003
Vidhyasekaran, P., N. Kamala, A. Ramanathan, K. Rajappan and V. Paranidharan et al., 2001. Induction of systemic by Pseudomonas fluorescens Pfi against Xanthomonas oryzae pv. Oryzae in rice leaves. Phytoparasitica, 29: 155-166. DOI: 10.1007/BF02983959

Zhang, F., N. Dashti, H. Hynes and D.L. Smith, 1996. Plant growth promoting rhizobacteria and soybean (Glicine $\max$ L. Merr.) nodulation and nitrogen fixation at suboptimal root zone temperatures. Ann. Bot. 77: 453-459. DOI: 10.1023/A:1004358100856

Zhang, Y., Z. Zhou, X. Ma and G. Jin, 2010. Foraging ability and growth performance of four subtropical tree species in response to heterogeneous nutrient environments. J. Forest Res., 2: 91-98. DOI: 10.1007/s10310-009-0153-5 